\title{
Hepatic Hemangioma in Celiac Patients: Data from a Large Consecutive Series
}

\author{
Sara Massironi, ${ }^{1}$ Federica Branchi, ${ }^{1,2}$ Roberta Elisa Rossi, ${ }^{1,2}$ Mirella Fraquelli, ${ }^{1}$ Luca Elli, \\ Maria Teresa Bardella, ${ }^{1}$ Federica Cavalcoli, ${ }^{1,2}$ and Dario Conte ${ }^{1,2}$ \\ ${ }^{1}$ Gastroenterology and Endoscopy Unit, Fondazione IRCCS Cà Granda Ospedale Maggiore Policlinico, Via Francesco Sforza 28, \\ 20122 Milan, Italy \\ ${ }^{2}$ Department of Pathophysiology and Transplantation, Università degli Studi di Milano, Via Francesco Sforza 35, 20122 Milan, Italy
}

Correspondence should be addressed to Sara Massironi; sara.massironi@policlinico.mi.it

Received 16 October 2014; Accepted 24 December 2014

Academic Editor: Eldon A. Shaffer

Copyright (C) 2015 Sara Massironi et al. This is an open access article distributed under the Creative Commons Attribution License, which permits unrestricted use, distribution, and reproduction in any medium, provided the original work is properly cited.

\begin{abstract}
Background and Aims. Hepatic hemangioma $(\mathrm{HH})$ has a widely ranging prevalence. The etiology is unclear; however, associations with autoimmune disorders have been described. We aimed at evaluating the prevalence of HH in celiac disease. Methods. Ninetyseven consecutive patients with celiac disease ( $18 \mathrm{M}, 79 \mathrm{~F}$, median age 41, and range 17-84 years) underwent liver ultrasound between January 2011 and 2012. The findings were compared with those of 1352 nonceliac patients $(581 \mathrm{M}, 771 \mathrm{~F}$, median age 50, and range 16-94 years), without liver disease or previously detected HH, who underwent US in the same period. Results. Ultrasonographic findings consistent with $\mathrm{HH}$ were observed in 14 celiac patients (14.4\%), a prevalence significantly higher than in controls (69 cases, 5.1\%) $(P=0.0006)$. Subgroup analysis showed that, among women, the prevalence of HH was $16.4 \%$ in the celiac disease group $(13 / 79)$ compared with $5.9 \%$ in controls $(46 / 771)(P=0.002)$. In celiac setting, HH had a median diameter of $1.3 \mathrm{~cm}$ and presented as a single lesion in 12 cases (86\%). Conclusions. Our findings are consistent with a significantly higher prevalence of $\mathrm{HH}$ in celiac patients. Although mechanisms underlying this association remain unclear, autoimmune and metabolic processes, as well as alterations of gut-liver axis equilibrium, could play a role.
\end{abstract}

\section{Introduction}

Hepatic hemangioma ( $\mathrm{HH})$ is the most common benign mesenchymal hepatic tumor. It has a prevalence ranging from 3 to $20 \%$. The prevalence is highest in women $[1,2]$, and in most cases it is an incidental or autopsy finding [2, 3]. The pathogenesis is far from being clearly understood, although they are supposed to develop as a consequence of unregulated angiogenesis [4], influenced by either estrogen levels $[5,6]$ or genetic predisposition [7-12]. An association of $\mathrm{HH}$ with systemic lupus erythematosus (SLE) has also been reported, suggesting that $\mathrm{HH}$ might be considered a hepatic manifestation of autoimmune diseases [4].

HHs have never been reported in association with celiac disease $(\mathrm{CD})$, an immune-mediated enteropathy caused by permanent immunological intolerance to ingested gluten. Celiac disease occurs in genetically predisposed people and affects approximately $1 \%$ of the population in Western countries [13-15]. Many pathological conditions such as malignancy have been reported as a possible association with CD [16-22]. Hepatic disorders are common in CD [23, 24 ] and include steatosis, cryptogenic hypertransaminasemia [25], and autoimmune liver diseases [26]. Malabsorption [27], increased intestinal permeability [28, 29], bacterial overgrowth [30], and intestinal inflammation [31] have been reported as of relevance in the pathogenesis of liver injury in CD.

Alteration of the gut-liver axis equilibrium plays a major role in the development of immune disorders involving the small bowel and liver $[32,33]$. In celiac disease, the increased intestinal permeability may cause an increased flow of molecules to the liver through the portal circulation. These molecules can originate from the local immune reaction and the cross-linking between tissue transglutaminase and food or bacterial antigens [34]. There is high probability that chronic liver exposition to active molecules could lead 
to the development of certain liver diseases. Exposure of the liver to immunologically active molecules generated in the small bowel mucosa of CD patients or to high levels of angiogenic factors, such as vascular endothelial growth factor (VEGF), could, for instance, lead to the development of vascular lesions such as $\mathrm{HH}$. An overexpression of mucosal VEGF in CD patients, as already suggested in SLE [4], would be an attractive hypothesis.

As a consequence of previous observations made during routine clinical practice and based on data collected during a previous study by our group [35], we developed a hypothesis that $\mathrm{HH}$ could be a frequent finding in patients with CD. We have performed a retrospective analysis of a consecutive series of patients, with the aim of evaluating if the prevalence of $\mathrm{HH}$ in a celiac population was higher than that expected in the general population. This could lead to the underlining of a possible association with a multifactorial basis between $\mathrm{HH}$ and CD.

\section{Methods}

The study was carried out at the Gastroenterology and Endoscopy Unit, Fondazione IRCCS Ca' Granda, Ospedale Maggiore Policlinico, Milan (Italy).

A series of 97 consecutive patients affected by CD who were prospectively enrolled for another study by our group between January 2011 and January 2012 [35] underwent a complete abdominal ultrasound (US) as part of a thorough clinical evaluation.

US liver findings were compared with those of a consecutive series of nonceliac patients referred for abdominal US for unspecific gastrointestinal symptoms (i.e., dyspepsia, abdominal pain, and diarrhea) by our gastroenterology outpatient clinic during the same period.

All subjects gave their written informed consent to the study, which was approved by the local ethics committee.

2.1. Patients with CD. The diagnosis of CD was made according to currently accepted criteria [36] and was based on both serology and histology. Anti-endomysial antibodies were sought using direct immunofluorescence on monkey esophagus (Bio-Rad, Milan, Italy); positive staining around the smooth muscle was considered positive. Anti-transglutaminase antibodies were assessed by ELISA (Eurospital, Trieste, Italy); titres above 7 arbitrary units were considered positive [37, 38]. During upper gastrointestinal tract endoscopy, four biopsies were taken from the second portion of the duodenum and the histological diagnosis of CD was made according to the Marsh classification modified by Oberhuber et al. [39, 40]. All CD patients underwent complete abdominal US and clinical and laboratory parameters were collected.

2.2. Control Subjects. The control group consisted of consecutive nonceliac patients with persistently normal transaminases and no known liver diseases, who underwent abdominal US for unspecific gastrointestinal symptoms (i.e., dyspepsia, abdominal pain, and diarrhea) during the same period. Exclusion criteria for both groups included previously detected $\mathrm{HH}$ and/or presence of known liver disease (including chronic hepatitis $\mathrm{B}$ virus and hepatitis $\mathrm{C}$ virus infection, liver cirrhosis, and nonalcoholic steatohepatitis). For control subjects, additional exclusion criteria were known CD or suspected CD, defined as presence of either serological positivity or pathologic histology at the time of abdominal US.

2.3. US Studies. Abdominal US examinations were performed after an overnight fast, with a Philips iU22 system (Philips Ultrasound, Bothell, WA, USA), provided with a multifrequency convex transducer (C5-2, 5-2 MHz). A complete, standard gray-scale US examination of the upper abdomen was warranted for all patients. All examinations were obtained and evaluated in real time by two expert operators (MF and SM).

2.4. Diagnosis of $\mathrm{HH}$. HHs usually have typical sonographic features of round-shaped hyperechoic lesions although it may appear as a lesion with irregular shape or with hypoechoic pattern, especially in the context of liver steatosis.

After a first US finding of $\mathrm{HH}$, all patients referred to our clinic underwent US controls after 3 and 6 months in order to confirm the diagnosis and to assess stability of shape and size.

In cases where the sonographic features of the $\mathrm{HH}$ findings were not typical, patients underwent further radiological examination with magnetic resonance (MRI).

2.5. Statistical Analysis. The results are expressed as median and range, unless otherwise stated. All data were tested for a normal distribution using the Kolmogoroff-Smirnoff test. Differences between percentages were evaluated using Fisher's exact test. Differences between groups were evaluated by means of the Mann-Whitney and Kruskal-Wallis tests, followed by Dunn's multiple comparison test when appropriate. Correlation between variables was assessed by determining Spearman's coefficient. A $P$ value $<0.05$ was considered statistically significant.

\section{Results}

Ninety-seven consecutive patients (18 M, 79 F, median age 41 , and range 17-84 years) with confirmed CD were included in the study. Most of them (72, i.e., $74.2 \%$ ) were on an ongoing gluten-free diet regimen for a mean period of five years (range 1-31). A total of 1352 consecutive nonceliac patients $(581 \mathrm{M}, 771 \mathrm{~F}$, median age 50 , and range $16-94$ years) with persistently normal transaminases and no known liver diseases were included as control group. Demographic and clinical characteristics of the study groups are detailed in Table 1 .

In 14 of the 97 celiac patients (14.4\%) US findings were fully consistent with $\mathrm{HH}$, compared with 69 (5.1\%) in the control group $(P=0.0009)$.

As detailed in Table 2, HHs in celiac patients had a median diameter of $1.3 \mathrm{~cm}$ (range $0.6-6.8 \mathrm{~cm}$ ) and presented 
TABLE 1: Demographic and clinical characteristics in celiac disease (CD) patients and controls.

\begin{tabular}{lccc}
\hline & $\begin{array}{c}\text { CD } \\
(\# 97)\end{array}$ & $\begin{array}{c}\text { Controls } \\
(\# 1352)\end{array}$ & $P$ \\
\hline $\begin{array}{l}\text { Age (yrs), median } \\
\text { (range) }\end{array}$ & 41 & 50.5 & n.s. \\
Female, \# (\%) & $(17-84)$ & $(16-94)$ & \\
BMI $^{\S}$ 25-30, \# (\%) & $79(81)$ & $771(57)$ & $<0.0001$ \\
$\begin{array}{l}\text { Albumin (g/dL), median } \\
\text { (range) }\end{array}$ & $4(4.1)$ & $63(4.7)$ & n.s. \\
Steatosis, \# (\%) & 4.3 & 4.6 & n.s. \\
Grades 1, 2, and 3* & $(3.8-5.1)$ & $(4-5.1)$ & \\
\hline
\end{tabular}

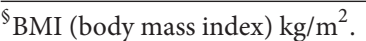

${ }^{*}$ Grade 1: attenuation in the posterior segments of the liver; Grade 2: loss of echoes from the diaphragm; Grade 3: loss of echoes from the walls of the portal vein.

TABLE 2: Characteristics of US findings in celiac disease (CD) patients and in controls.

\begin{tabular}{lccc}
\hline & $\begin{array}{c}\text { CD } \\
(\# 97)\end{array}$ & $\begin{array}{c}\text { Controls } \\
(\# 1352)\end{array}$ & $P$ \\
\hline $\begin{array}{l}\text { HH, \# } \\
(\%)\end{array}$ & 14 & 69 & 0.0009 \\
$\begin{array}{l}\text { Prevalence of HH by gender } \\
\quad \text { Females, \# (\%) }\end{array}$ & $13 / 79(16.4)$ & $46 / 771(5.9)$ & 0.002 \\
$\quad$ Males, \# (\%) & $1 / 18(5.6)$ & $23 / 581(3.9)$ & n.s. \\
$\begin{array}{l}\text { Number of lesions } \\
\quad \text { Single, \# (\%) }\end{array}$ & $12(85.7)$ & $59(85.5)$ & n.s. \\
$\quad$ Multiple, \# (\%) & $2(14.3)$ & $10(14.5)$ & n.s. \\
$\begin{array}{l}\text { HH diameter (cm); median } \\
\text { (range) }\end{array}$ & 1.3 & 1.5 & n.s. \\
Atypical features* , \# (\%) & $(0.3-6.8)$ & $(0.7-4.6)$ & \\
\hline
\end{tabular}

$\mathrm{HH}$ : hepatic hemangioma.

${ }^{*}$ Hypoechoic or isoechoic lesions, mixed echogenicity, lobulated mass, and blurred margins.

as a single lesion in 12 of the 14 patients (86\%). They appeared as hyperechoic lesions in 13 patients (93\%), without significant differences from the US findings in the control group, where the median diameter was $1.5 \mathrm{~cm}$ (range 0.7-4.6) and the lesion was single in 59 cases $(86 \%)$. In cases where the sonographic features of the $\mathrm{HH}$ findings were not typical (i.e., atypical shape, hypoechoic pattern), patients underwent further radiological examination with magnetic resonance (MRI), which confirmed the diagnosis (1 patient in the CD group and 11 patients in the control group).

The prevalence of female gender was higher in $\mathrm{CD}$ than in the control population $(P<0.0001)$. The two groups were indeed similar in regard to age and presence of steatosis (the latter was present in $37 \%$ of $\mathrm{CD}$ patients versus $34.6 \%$ of control subjects, $P=$ n.s.).

The prevalence of $\mathrm{HH}$ was $5.6 \%$ in male celiac patients (1/18) compared with $3.9 \%$ in nonceliac patients $(23 / 581)$ $(P=$ n.s. $)$. Among women, the prevalence was $16.4 \%$ in

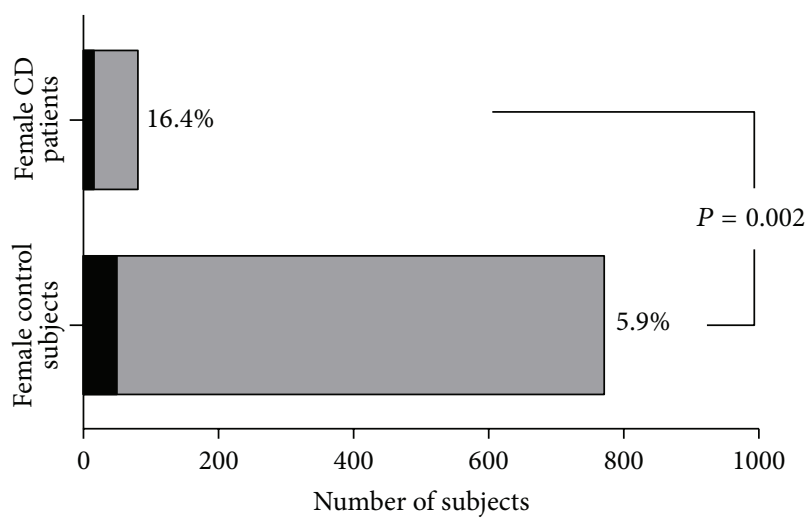

$\mathrm{HH}$

FIGURE 1: Prevalence of hepatic hemangioma $(\mathrm{HH})$ in female $\mathrm{CD}$ patients and in female control subjects. $y$-axis: female control subjects and female CD patients; $x$-axis: number of subjects.

the $\mathrm{CD}$ group (13/79) versus $5.9 \%$ in the control group (46/771) (Figure $1, P=0.002$ ).

\section{Discussion}

Results from this series suggest a higher $\mathrm{HH}$ prevalence in $\mathrm{CD}$ than in controls, delineating a previously unreported association. Indeed, the prevalence of $\mathrm{HH}$ at US liver scan was about three times higher in $\mathrm{CD}$ than in controls, the difference being even higher in women.

This study represents the first series aimed at evaluating the possible association between $\mathrm{HH}$ and $\mathrm{CD}$. In this context, it is of relevance that both the large control group and the inclusion and exclusion criteria make this group highly representative of the general population. Firstly, patients with existing liver disease were excluded from the study because the sonographic diagnosis of $\mathrm{HH}$ would have been extremely difficult in this specific setting, requiring more than one imaging technique to avoid a misdiagnosis of liver malignancy. Additionally, patients with already known $\mathrm{HH}$ were excluded, due to the risk of bias from extremely high prevalence of patients with known focal liver lesions referred to our tertiary center for consultation and repeat US scans. Excluding these patients, the observed prevalence of $5.1 \%$ of US findings of $\mathrm{HH}$ in the control group is consistent with epidemiological data in the general population [1-3].

A point of weakness of this series is the relatively small number of male subjects in the CD group. In fact, both groups had a higher prevalence of female subjects, particularly relevant in the $\mathrm{CD}$ group (79 versus 18), reflecting the higher prevalence of the disease in females [41, 42]. The finding of only one $\mathrm{HH}$ among the 18 male $\mathrm{CD}$ patients precludes any conclusions. This suggests the need for collecting a larger number of male $C D$ patients in future series, to both improve the statistical power of US findings and help in clarifying the potential influence of estrogen. 
A second aspect of weakness is that at present MRI is generally considered the reference standard for detecting $\mathrm{HH}$. In this study MRI was actually performed only when facing large $\mathrm{HHs}$ or lesions with atypical features. There are conflicting recommendations regarding the management of patients with US findings consistent with "typical" $\mathrm{HH}$ and it is a matter of discussion whether the diagnostic accuracy of US is sufficient for a correct diagnosis of $\mathrm{HH}$, mainly in the setting of patients with liver steatosis, which was detected in more than one-third of $\mathrm{CD}$ patients and controls. Aiming at increasing the diagnostic performance of US liver scan, US examinations were performed by two operators (MF and SM) with large experience in the field.

Another point to consider is the prevalence of single $\mathrm{HH}$ at US. In both CD patients and controls $\mathrm{HH}$ was detected as a single lesion in nearly $86 \%$ of the cases. It is commonly believed that $\mathrm{HH}$ is often solitary, but available data support the hypothesis that multiple lesions could be present in up to $40 \%$ of patients $[1,2]$. However, as scattered data are available about the US detection rate of multiple versus single lesions, a $14 \%$ rate of detection of multiple $\mathrm{HH}$ in both groups, without a significant difference, suggests a satisfying accuracy for this imaging technique.

The mechanisms underlying the possible association between $\mathrm{HH}$ and $\mathrm{CD}$ are still far from clearly understood. However, hormonal, autoimmune, genetic and metabolic processes could play a role.

Firstly, $\mathrm{HH}$ and $\mathrm{CD}$ are known to be more common in females. This could partially explain the association of $\mathrm{CD}$ and $\mathrm{HH}$ detected in our study, suggesting a potential role of estrogen as triggering factor. However, we also observed an increased prevalence of $\mathrm{HH}$ in the $\mathrm{CD}$ male group $(5.6 \%$ versus $3.9 \%$ ), although the data did not reach statistical significance. Moreover, estrogen receptors have not been found in all HHs, and hemangioma growth may also occur in postmenopausal women, independent of hormonal influence [3].

Secondly, Berzigotti et al. reported fivefold increased odds of HH in a series of SLE patients, suggesting that $\mathrm{HH}$ might be considered among the hepatic manifestations of SLE [4]. Since SLE is considered an autoimmune disorder, as is $\mathrm{CD}$, autoimmunity could also play an important role. However, the exact autoimmune mechanisms potentially involved remain to be elucidated.

Moreover, as already suggested in SLE [4], an overexpression of angiogenic factors, particularly vascular endothelial growth factor (VEGF), in CD patients would be an attractive hypothesis even if further studies are needed in this context. It has been suggested that hemangiomas could be related to a dysregulated angiogenesis due to an imbalance between angiogenic and angiostatic factors [43]. The alteration of gut-liver axis equilibrium due to the increased intestinal permeability in $\mathrm{CD}$ may cause a flow of active molecules to the liver through the portal circulation [34]. Liver exposure to high levels of angiogenic factors could lead to the development of vascular lesions. However, in this study, data supporting this hypothesis are lacking, because blood and mucosal VEGF and other proangiogenic cytokines were not determined. Kitajima et al. [44] studied a transgenic rabbit model with increased liver expression of the human VEGF, whose upregulation has already been reported in association with hemangiomas. In that study, the overexpression of VEGF in the liver was determined to be sufficient for inducing hemangiomas. Moreover, transgenic rabbits developed hemolytic anemia, thrombocytopenia, and splenomegaly, all possible features of genetic syndromes such as KasabachMerrit syndrome [7]; thus, the above model could be useful in elucidating the mechanism underlying the development of $\mathrm{HH}$ and related complications.

Finally, another possible explanation could be a common genetic pathway, since familial or genetic patterns of inheritance have been hypothesized in both $\mathrm{CD}$ and $\mathrm{HH}$. CD usually develops in genetically predisposed patients, with a strong association with HLA-DQ genes [13]. On the other hand, HHs have been described as part of defined clinical syndrome and, according to some authors, hemangiomas may be indicators of serious syndromes. However, no patient included in this study was affected by a genetic syndrome.

\section{Conclusions}

Overall, as from our data, $\mathrm{HH}$ prevalence seems to be significantly higher in $\mathrm{CD}$ patients than in the general population. Further studies are needed both to confirm this data and to explain the possible pathogenetic pathways, before suggesting that all patients with US findings consistent with $\mathrm{HH}$ should be screened for CD.

\section{Conflict of Interests}

All the authors declare that there is no conflict of interests regarding the publication of this paper.

\section{References}

[1] L. Gandolfi, P. Leo, L. Solmi, E. Vitelli, G. Verros, and A. Colecchia, "Natural history of hepatic haemangiomas: clinical and ultrasound study," Gut, vol. 32, no. 6, pp. 677-680, 1991.

[2] K. R. Reddy, "Benign and Solid tumors of the liver: relationship to sex, age, size of tumors, and outcome," American Surgeon, vol. 67, no. 2, pp. 173-178, 2001.

[3] R. Bahirwani and K. R. Reddy, "Review article: the evaluation of solitary liver masses," Alimentary Pharmacology \& Therapeutics, vol. 28, no. 8, pp. 953-965, 2008.

[4] A. Berzigotti, M. Frigato, E. Manfredini et al., "Liver hemangioma and vascular liver diseases in patients with systemic lupus erythematosus," World Journal of Gastroenterology, vol. 17, no. 40, pp. 4503-4508, 2011.

[5] T. Saegusa, K. Ito, N. Oba et al., "Enlargement of multiple cavernous hemangioma of the liver in association with pregnancy," Internal Medicine, vol. 34, no. 3, pp. 207-211, 1995.

[6] V. Glinkova, O. Shevah, M. Boaz, A. Levine, and H. Shirin, "Hepatic haemangiomas: possible association with female sex hormones," Gut, vol. 53, no. 9, pp. 1352-1355, 2004.

[7] B. Frider, A. Bruno, J. Selser, R. Vanesa, P. Pascual, and R. Bistoletti, "Kasabach-Merrit syndrome and adult hepatic epithelioid hemangioendothelioma an unusual association," Journal of Hepatology, vol. 42, no. 2, pp. 282-283, 2005. 
[8] K. Takahashi, K. Iida, Y. Okimura et al., "A novel mutation in the von Hippel-Lindau tumor suppressor gene identified in a Japanese family with pheochromocytoma and hepatic hemangioma," Internal Medicine, vol. 45, no. 5, pp. 265-269, 2006.

[9] E. Cureton, H. Guo, O. Idowu, and S. Kim, "Hepatic vascular malformation in a patient with Simpson-Golabi-Behmel syndrome," The American Journal of Medical Genetics, Part A, vol. 143, no. 12, pp. 1379-1381, 2007.

[10] S. H. Teh, G. B. Ong, and T. S. Hean, "Early presentation of right adrenal mass, hepatoblastoma and hepatic cavernous haemangioma in Beckwith-Wiedemann syndrome," Medical Journal of Malaysia, vol. 62, no. 4, pp. 345-346, 2007.

[11] R. Pezzilli, C. Serra, P. Tomassetti, E. Brocchi, D. Campana, and R. Corinaldesi, "Maffucci syndrome with hemangioma of the liver," Case Reports in Gastroenterology, vol. 3, no. 1, pp. 1-4, 2009.

[12] U. M. Sahiner, S. Senel, N. Erkek, C. Karacan, and A. Yoney, "Rubinstein Taybi syndrome with hepatic hemangioma," Medical Principles and Practice, vol. 18, no. 2, pp. 162-164, 2009.

[13] L. M. Sollid, G. Markussen, J. Ek, H. Gjerde, F. Vartdal, and E. Thorsby, "Evidence for a primary association of celiac disease to a particular HLA-DQ $\alpha / \beta$ heterodimer," The Journal of Experimental Medicine, vol. 169, no. 1, pp. 345-350, 1989.

[14] M. T. Bardella, L. Elli, P. Velio, C. Fredella, L. Prampolini, and B. Cesana, "Silent celiac disease is frequent in the siblings of newly diagnosed celiac patients," Digestion, vol. 75, no. 4, pp. 182-187, 2007.

[15] G. J. Tack, W. H. M. Verbeek, M. W. J. Schreurs, and C. J. J. Mulder, "The spectrum of celiac disease: epidemiology, clinical aspects and treatment," Nature Reviews Gastroenterology \& Hepatology, vol. 7, no. 4, pp. 204-213, 2010.

[16] J. P. Farcet, P. Gaulard, J. P. Marolleau et al., "Hepatosplenic T-cell lymphoma: sinusal/sinusoidal localization of malignant cells expressing the T-cell receptor $\gamma \delta$," Blood, vol. 75, no. 11, pp. 2213-2219, 1990.

[17] K. Blakolmer, P. Gaulard, C. Mannhalter et al., "Unusual peripheral $\mathrm{T}$ cell lymphoma presenting as acute liver failure and reappearing in the liver allograft," Transplantation, vol. 70, no. 12, pp. 1802-1805, 2000.

[18] J. Askling, M. Linet, G. Gridley, T. S. Halstensen, K. Ekström, and A. Ekbom, "Cancer incidence in a population-based cohort of individuals hospitalized with celiac disease or dermatitis herpetiformis," Gastroenterology, vol. 123, no. 5, pp. 1428-1435, 2002.

[19] H. J. Freeman, "Lymphoproliferative and intestinal malignancies in 214 patients with biopsy-defined celiac disease," Journal of Clinical Gastroenterology, vol. 38, no. 5, pp. 429-434, 2004.

[20] N. Brousse and J. W. R. Meijer, "Malignant complications of coeliac disease," Best Practice and Research: Clinical Gastroenterology, vol. 19, no. 3, pp. 401-412, 2005.

[21] C. Catassi, I. Bearzi, and G. K. T. Holmes, "Association of celiac disease and intestinal lymphomas and other cancers," Gastroenterology, vol. 128, no. 4, pp. S79-S86, 2005.

[22] H. J. Freeman, "Malignancy in adult celiac disease," World Journal of Gastroenterology, vol. 15, no. 13, pp. 1581-1583, 2009.

[23] A. Rubio-Tapia and J. A. Murray, "The liver in celiac disease," Hepatology, vol. 46, no. 5, pp. 1650-1658, 2007.

[24] U. Volta, "Pathogenesis and clinical significance of liver injury in celiac disease," Clinical Reviews in Allergy \& Immunology, vol. 36, no. 1, pp. 62-70, 2009.
[25] M. T. Bardella, M. Vecchi, D. Conte et al., "Chronic unexplained hypertransaminasemia may be caused by occult celiac disease," Hepatology, vol. 29, no. 3, pp. 654-657, 1999.

[26] F. Mirzaagha, S. H. Azali, F. Islami et al., "Coeliac disease in autoimmune liver disease: a cross-sectional study and a systematic review," Digestive and Liver Disease, vol. 42, no. 9, pp. 620-623, 2010.

[27] H. J. Freeman, "Hepatobiliary and pancreatic disorders in celiac disease," World Journal of Gastroenterology, vol. 12, no. 10, pp. 1503-1508, 2006.

[28] T. Lindberg, N. O. Berg, S. Borulf, and I. Jakobsson, "Liver damage in coeliac disease or other food intolerance in childhood," The Lancet, vol. 1, no. 8060, pp. 390-391, 1978.

[29] G. Novacek, W. Miehsler, F. Wrba, P. Ferenci, E. Penner, and H. Vogelsang, "Prevalence and clinical importance of hypertransaminasaemia in coeliac disease," European Journal of Gastroenterology and Hepatology, vol. 11, no. 3, pp. 283-288, 1999.

[30] F. M. Stevens and R. M. McLoughlin, "Is coeliac disease a potentially treatable cause of liver failure?" European Journal of Gastroenterology \& Hepatology, vol. 17, no. 10, pp. 1015-1017, 2005.

[31] I. R. Korponay-Szabó, T. Halttunen, Z. Szalai et al., "In vivo targeting of intestinal and extraintestinal transglutaminase 2 by coeliac autoantibodies," Gut, vol. 53, no. 5, pp. 641-648, 2004.

[32] Y. S. Seo and V. H. Shah, "The role of gut-liver axis in the pathogenesis of liver cirrhosis and portal hypertension," Clinical and Molecular Hepatology, vol. 18, no. 4, pp. 337-346, 2012.

[33] O. E. Frasinariu, S. Ceccarelli, A. Alisi, E. Moraru, and V. Nobili, "Gut-liver axis and fibrosis in nonalcoholic fatty liver disease: an input for novel therapies," Digestive and Liver Disease, vol. 45, no. 7, pp. 543-551, 2013.

[34] U. Volta, G. Caio, F. Tovoli, and R. de Giorgio, "Gut-liver axis: an immune link between celiac disease and primary biliary cirrhosis," Expert Review of Gastroenterology and Hepatology, vol. 7, no. 3, pp. 253-261, 2013.

[35] S. Massironi, R. E. Rossi, M. Fraquelli et al., "Transient elastography in patients with celiac disease: a noninvasive method to detect liver involvement associated with celiac disease," Scandinavian Journal of Gastroenterology, vol. 47, no. 6, pp. 640648, 2012.

[36] A. Rubio-Tapia and J. A. Murray, "Celiac disease," Current Opinion in Gastroenterology, vol. 26, no. 2, pp. 116-122, 2010.

[37] I. D. Hill, "What are the sensitivity and specificity of serologic tests for celiac disease? Do sensitivity and specificity vary in different populations?" Gastroenterology, vol. 128, no. 4, pp. S25-S32, 2005.

[38] N. R. Lewis and B. B. Scott, "Systematic review: the use of serology to exclude or diagnose coeliac disease (a comparison of the endomysial and tissue transglutaminase antibody tests)," Alimentary Pharmacology \& Therapeutics, vol. 24, no. 1, pp. 4754, 2006.

[39] M. N. Marsh, "Gluten, major histocompatibility complex, and the small intestine: a molecular and immunobiologic approach to the spectrum of gluten sensitivity ('celiac sprue')," Gastroenterology, vol. 102, no. 1, pp. 330-354, 1992.

[40] G. Oberhuber, G. Granditsch, and H. Vogelsang, "The histopathology of coeliac disease: time for a standardized report scheme for pathologists," European Journal of Gastroenterology and Hepatology, vol. 11, no. 10, pp. 1185-1194, 1999. 
[41] P. H. R. Green, S. N. Stavropoulos, S. G. Panagi et al., "Characteristics of adult celiac disease in the USA: results of a national survey," The American Journal of Gastroenterology, vol. 96, no. 1, pp. 126-131, 2001.

[42] H. J. Thomas, T. Ahmad, C. Rajaguru, M. Barnardo, B. F. Warren, and D. P. Jewell, "Contribution of histological, serological, and genetic factors to the clinical heterogeneity of adult-onset coeliac disease," Scandinavian Journal of Gastroenterology, vol. 44, no. 9, pp. 1076-1083, 2009.

[43] J. Folkman, "Tumor angiogenesis and tissue factor," Nature Medicine, vol. 2, no. 2, pp. 167-168, 1996.

[44] S. Kitajima, E. Liu, M. Morimoto et al., "Transgenic rabbits with increased VEGF expression develop hemangiomas in the liver: a new model for Kasabach-Merritt syndrome," Laboratory Investigation, vol. 85, no. 12, pp. 1517-1527, 2005. 


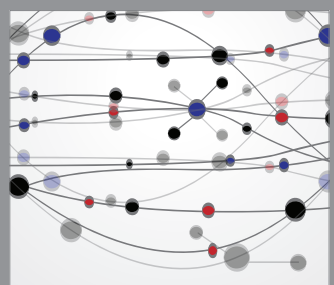

The Scientific World Journal
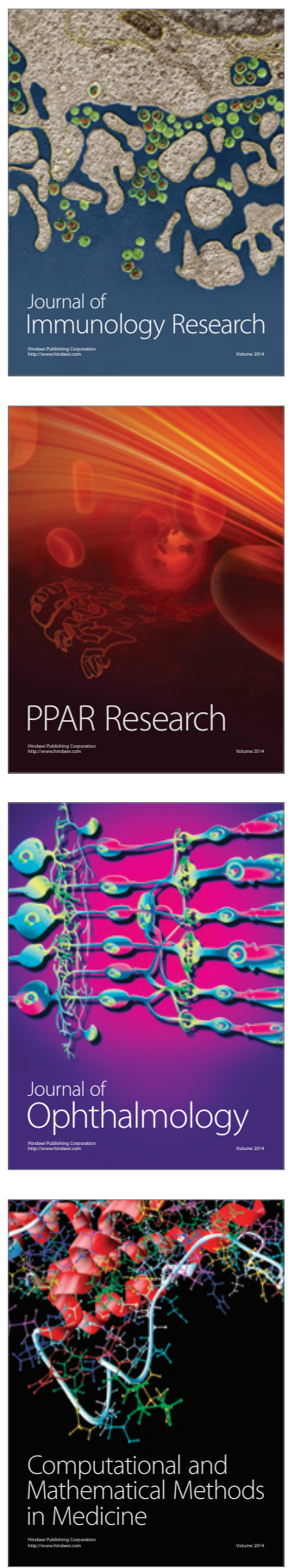

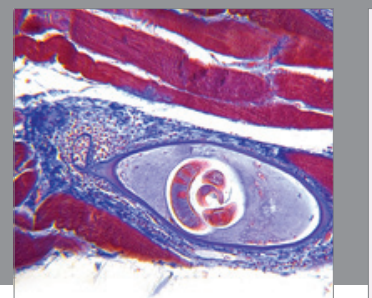

Gastroenterology

Research and Practice
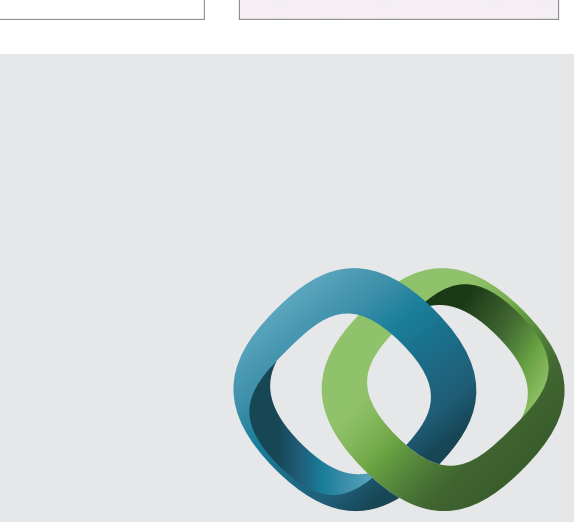

\section{Hindawi}

Submit your manuscripts at

http://www.hindawi.com
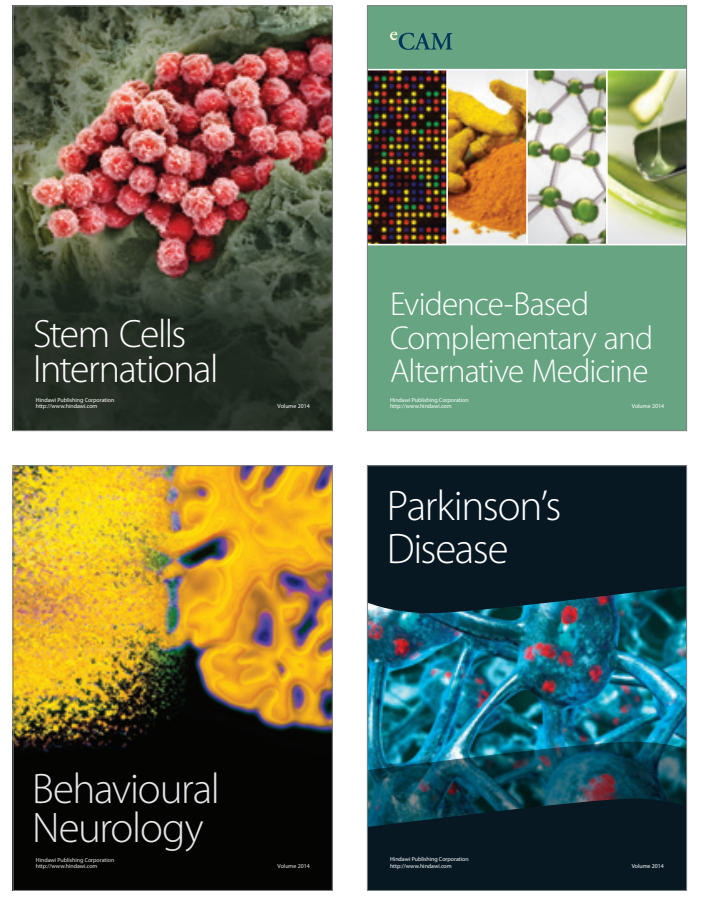
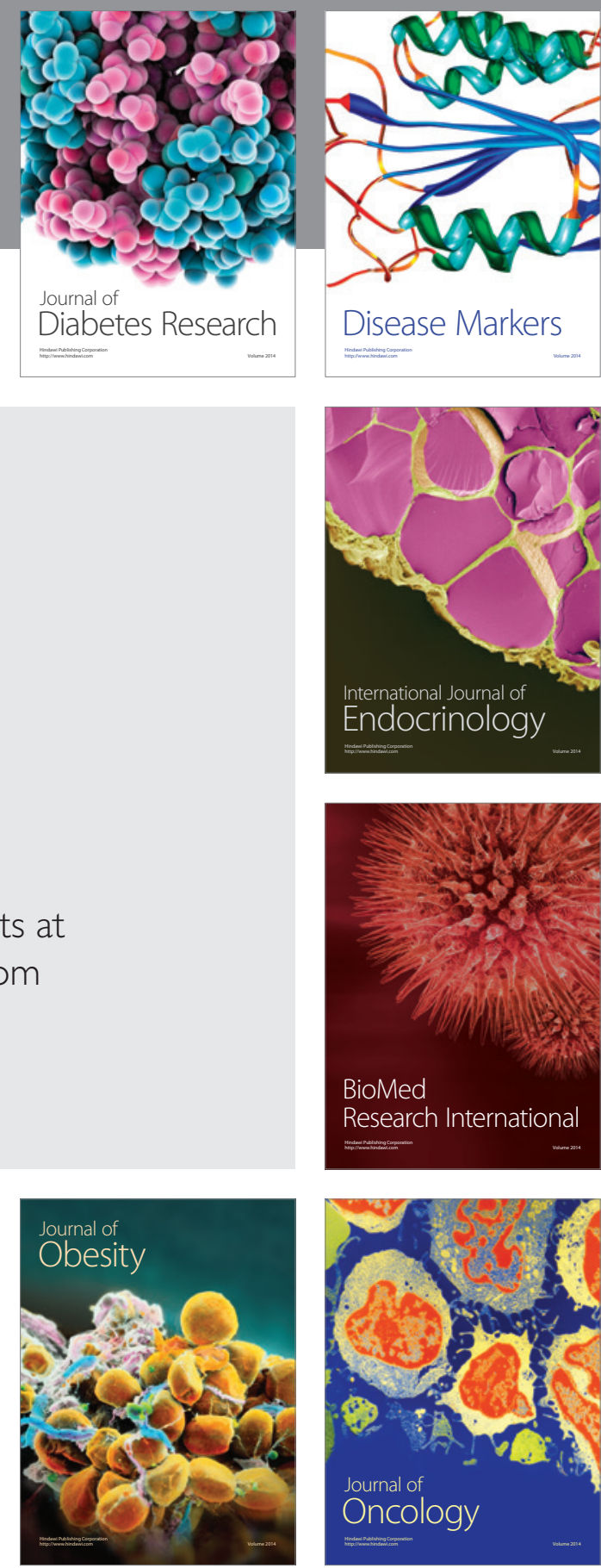

Disease Markers
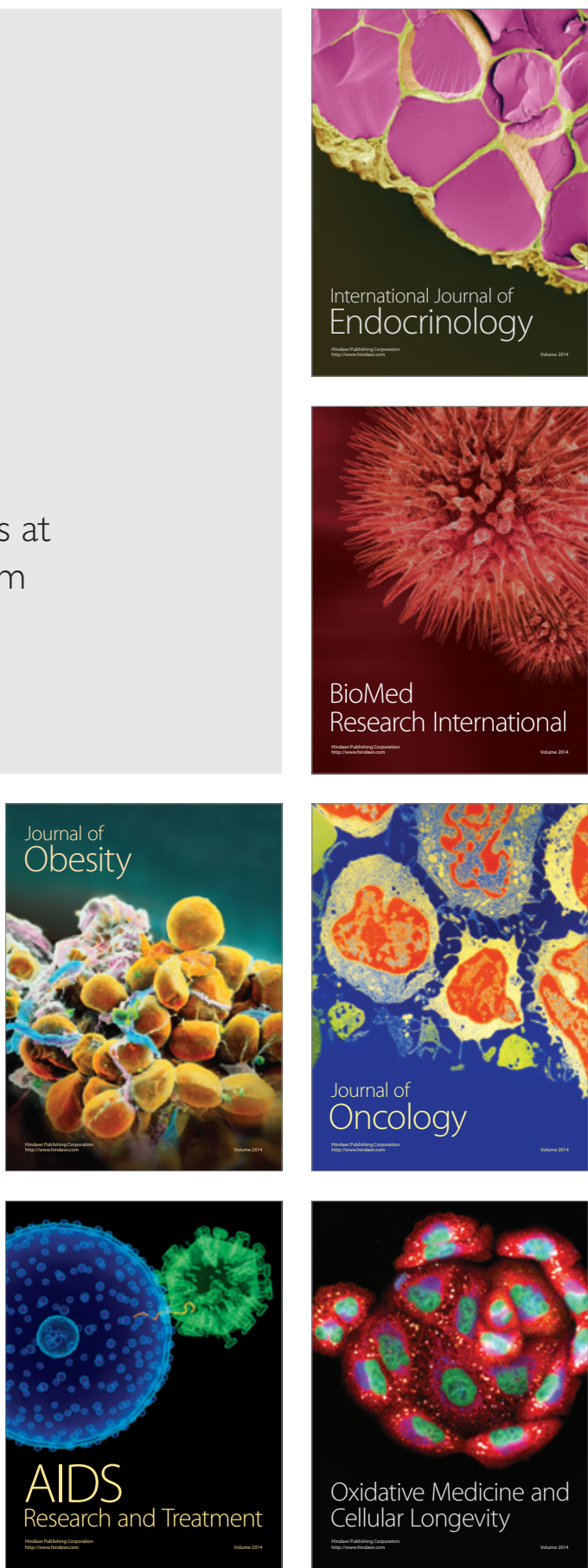